九州大学学術情報リポジトリ

Kyushu University Institutional Repository

\title{
Helicobacter pylori status and esophagogastroduodenal mucosal lesions in patients with end-stage renal failure on maintenance hemodialysis
}

Moriyama, Tomohiko

Department of Medicine and Clinical Science, Graduate School of Medical Sciences, Kyushu University

Matsumoto, Takayuki

Department of Medicine and Clinical Science, Graduate School of Medical Sciences, Kyushu University

Hirakawa, Katsuya

Division of Gastroenterology, Fukuoka Red Cross Hospital

Ikeda, Hirofumi

Department of Medicine and Clinical Science, Graduate School of Medical Sciences, Kyushu University

他

http://hdl. hand le. net/2324/26644

出版情報: Journal of Gastroenterology. 45 (5)， pp.515-522，2010-05. Springer Japan バージョン:

権利関係: (C) Springer 2010 


\section{Helicobacter pylori Status and Esophagogastroduodenal Mucosal Lesions in Patients with End-Stage Renal Failure on Maintenance Hemodialysis}

Short title: Upper GI lesion in patients on HD

Tomohiko Moriyama, MD, ${ }^{1}$ Takayuki Matsumoto, $\mathrm{MD},{ }^{1}$ Katsuya Hirakawa, $\mathrm{MD},{ }^{2}$

Hirofumi Ikeda, MD, ${ }^{1}$ Kazuhiko Tsuruya, MD,${ }^{1}$ Hideki Hirakata, MD,${ }^{1,3}$ and Mitsuo Iida, $\mathrm{MD}^{1}$

${ }^{1}$ Department of Medicine and Clinical Science, Graduate School of Medical Sciences, Kyushu University, Fukuoka;

Divisions of ${ }^{2}$ Gastroenterology and ${ }^{3}$ Nephrology, Fukuoka Red Cross Hospital, Fukuoka, Japan

Correspondence and reprint requests to:

Tomohiko Moriyama, MD, Department of Medicine and Clinical Science, Graduate School of Medical Sciences, Kyushu University, Maidashi 3-1-1, Higashi-ku, Fukuoka 812-8582, Japan Phone: +81-92-642-5261

Fax: +81-92-642-5273

E-mail: morimori@intmed2.med.kyushu-u.ac.jp 


\begin{abstract}
Objectives: The aim was to clarify the impact of Helicobacter $(H$.$) pylori infection on$ esophagogastroduodenal mucosal lesions in patients with end-stage renal failure on maintenance hemodialysis (HD).
\end{abstract}

Methods: Upper endoscopy and ${ }^{13} \mathrm{C}$-urea breath test were performed in 198 patients on maintenance HD. Clinical features, serum pepsinogen levels and esophagogastroduodenal mucosal lesions were compared between $H$. pylori-positive and -negative patients. Risk factors associated with esophagogastroduodenal mucosal lesion were determined by multivariate analyses.

Results: Upper endoscopy revealed that gastric erosion was the most frequent (58\%) followed by duodenal erosion (18\%), gastric ulcer (14\%), gastroesophageal reflux disease (10\%), and duodenal ulcer (7\%). 81 patients were positive and 117 patients were negative for H. pylori infection. Time duration after the introduction of HD was significantly longer and serum pepsinogen I/II ratio was significantly higher in $H$. pylori-negative patients than in $H$. pylori-positive patients. Multivariate analyses revealed $H$. pylori infection to be an independent, protective factor for gastric erosion (odds ratio $0.38 ; 95 \%$ confidence interval 0.21-0.70), while the infection was unrelated to other mucosal lesions.

Conclusions: Gastric erosion seems to be a mucosal lesion commonly seen in patients on maintenance HD. The high prevalence may be explained partly by the cure of $H$. pylori infection during the clinical course of maintenance HD.

Key words: end-stage renal failure, hemodialysis, Helicobacter pylori, ulcers, upper gastrointestinal tract. 


\section{Introduction}

Dyspeptic symptoms are common in patients with end-stage renal failure (ESRF), who undergo maintenance hemodialysis (HD). ${ }^{1}$ Because anti-coagulant therapy is inevitable during HD procedures, upper gastrointestinal bleeding occurs frequently in patients with ESRF on maintenance HD. ${ }^{2}$ However, there have been conflicting data on the prevalence of gastroduodenal mucosal lesions in patients on maintenance HD. ${ }^{3,4}$ Doherty et al. ${ }^{3}$ reported that most of the patients with chronic renal failure had gastrointestinal complications, while others found that the prevalence of peptic ulceration is only $2 \%$ in patients with chronic renal failure. ${ }^{4}$

It is widely accepted that Helicobacter pylori $(H$. pylori) plays an important role in the pathogenesis of chronic gastritis and gastric ulcer. ${ }^{5}$ While the prevalence of gastroduodenal mucosal lesion in patients with chronic renal failure has been shown to be equivalent to or higher than healthy patients, ${ }^{3,4}$ it still remains controversial as to the prevalence of $H$. pylori infection in patients undergoing HD. ${ }^{6-10}$ We thus attempted a multi-center, prospective and observational investigation for patients on maintenance HD to determine the prevalence of esophagogastroduodenal mucosal lesions and the impact of $H$. pylori infection on those lesions.

\section{Materials and Methods}

\section{Patients and protocol}

This study was conducted prospectively for ESRF patients on maintenance HD at 23 institutions or clinics in Fukuoka City during a period from March 2002 to August 2004. Patients who had been on maintenance HD for more than 1 month were asked to participate this endoscopic surveillance program. After being informed of the aim and the protocol of the investigation by the attending nephrologists, patients who agreed with the participation were recruited for the following examination.

After obtaining written informed consent, patients were examined at one of the institutions or clinics, where gastroenterologists performed esophagogastroduodenoscopy 
(EGD) and other examinations. It is well known that proton pump inhibitor intake cause false-negative result on urea breath test. ${ }^{11}$ Since one of the main objectives of the investigation was the prevalence of $H$. pylori infection, we excluded patients who had been taking proton pump inhibitor or who had a history of gastric surgery. The protocol of this investigation was conducted in accordance with the Helsinki Declaration.

\section{Endoscopic examination}

All patients underwent EGD, using a forward-viewing endoscope (Olympus, Tokyo, Japan) on the day not scheduled for HD. Endoscopic examinations were performed by endoscopists who had participated in consensus meetings for the determination of endoscopic findings prior to the study. The mucosal lesions were classified according to the "minimal standard terminology' established by World Organization of Digestive Endoscopy $(\mathrm{OMED})^{12}$. After an overnight fast, patients were prepared by topical anesthesia with $8 \%$ lidocaine solution. Under endoscopy, the subjects were assessed with respect to the presence and the location of reflux esophagitis, gastric ulcer, gastric erosion, duodenal ulcer, duodenal erosion, cancer and other types of lesions. Reflux esophagitis was regarded to be positive when at least one or more areas of reddish mucosa or mucosal defects were seen at the esophagocardial junction. ${ }^{13}$ Thus, esophagitis greater than grade $\mathrm{M}$ in modified Los Angeles classification for reflux esophagtis ${ }^{13,14}$ was regarded to be positive for reflux esophagitis. An ulcer was defined as an area of mucosal break with obvious whitish exudate, which was measuring more than $5 \mathrm{~mm}$ in its largest size. The size of each ulcer was determined in comparison with biopsy forceps. Ulcers, which were obviously larger than the size of the opened forceps, were regarded to be $>5 \mathrm{~mm}$ in size. Other mucosal breaks with reddened areas in the stomach or in the duodenum were judged to be erosions. In principle, biopsy specimens were not obtained from mucosal lesions. However, sampling of one or two biopsy specimens was permitted for a lesion, which was suspected of being malignant tumor.

\section{Assessment of $H$. pylori infection}

H. pylori infection was determined using ${ }^{13} \mathrm{C}$-urea breath test $\left({ }^{13} \mathrm{C}\right.$-UBT $)$ on the day of 
and just prior to EGD. Granular powder or a tablet of $100 \mathrm{mg}{ }^{13} \mathrm{C}$-urea was administered orally with $100 \mathrm{ml}$ tap water. Exhaled breath samples were taken at baseline and 20 minutes after consumption of the urea. The ${ }^{13} \mathrm{C}$ enrichment in breath was measured by isotope ratio mass spectrometer. The ${ }^{13} \mathrm{C}$-UBT was considered positive if the $\partial$-value at 20 minutes was $>2.5 \%$ o when compared to the baseline value. In this study, we did not apply rapid urease test for the diagnosis of $H$. pylori infection in order to minimize the number of tissue sampling.

\section{Other clinical variables}

Clinical variables of each patient on the day of endoscopy were verified on the basis of the clinical records at the referral nephrology institution. The variables included, age, gender, duration of $\mathrm{HD}$, and medications for ESRF, cardiovascular system, and upper gastrointestinal tract. The medications included anti-hypertensive drugs (angiotensin converting enzyme inhibitors, calcium antagonists, beta-blockers and diuretics), calcium and vitamin supplements, phosphate binders (calcium acetate and calcium carbonate), and gastroprotective drugs (histamine-2 receptor antagonist [H2RA] and mucosal protective drugs). In addition, possible use of non-steroidal anti-inflammatory drugs (NSAIDs) and prednisolone was also verified.

We also measured fasting serum pepsinogens (PGs) I and II on the day of endoscopy. Blood samples were obtained just prior to endoscopy and stored at $4{ }^{\circ} \mathrm{C}$ in a refrigerator until assay for PG I and II. The measurement of serum PG concentration was carried out by immunoradiometric assay (PG I/II RIA BEAD; Dainabot Co. Ltd., Tokyo, Japan), in accordance with the procedure described elsewhere. ${ }^{15}$

Statistical analysis

Comparisons between the groups were performed, using the chi-squared test, Fisher's exact test or Mann-Whitney's U test. Logistic regression analysis was carried out to evaluate the independent influence of each variables (sex, age, duration of $\mathrm{HD}$, drug consumption and $H$. pylori infection) to upper gastrointestinal lesions in patients undergoing maintenance HD. Probabilities less than 0.05 were considered to be significant. 


\section{Results}

\section{Demographic data}

During the investigation period, 220 patients on HD were listed up as the possible participants to the study. After excluding patients who had been taking proton pump inhibitor, informed consent was obtained from 198 patients. All these patients successfully underwent EGD, breath test and blood sampling for PG. The patients comprised 116 males and 82 females with ages ranging from 16 to 88 years $(61.3 \pm 11.6$ years, mean \pm SD). Their primary renal disease was chronic glomerulonephritis $(n=118)$, diabetic nephropathy $(n=54)$, hypertensive nephropathy $(n=12)$, and polycystic kidney disease $(n=5)$, while it was unknown in the remaining nine patients. Mean duration of HD until the entry ranged from 1 month to 49 years $(7.6 \pm 7.3$ years $)$.

Endoscopically, esophagogastroduodenal mucosal lesion was detected in 148 (75\%) patients. In addition, there were three cases of malignant neoplasm (gastric cancer in two cases and malignant lymphoma in a case) and a case of gastric antral vascular ectasia. Durations of HD in three patients with gastric malignant neoplasm were 10 months, 20 months and 84 months. Serum concentrations of PG I ranged from 22.2 to $944.0 \mathrm{pg} / \mathrm{ml}(266.0 \pm 160.1 \mathrm{pg} / \mathrm{ml})$ and PG II from 4.9 to $160.0 \mathrm{pg} / \mathrm{ml}(31.4 \pm 26.3 \mathrm{pg} / \mathrm{ml})$. The PG I/II ratio ranged from 1.4 to 22.7

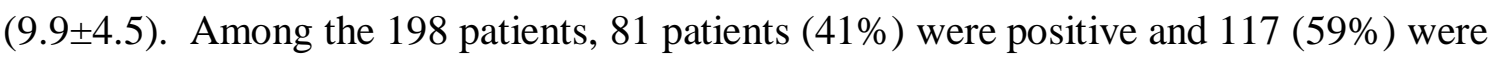
negative for $H$. pylori infection.

\section{Comparison of clinical features between $H$. pylori-positive and negative patients}

Table 1 summarizes the comparison of clinical findings between $H$. pylori-positive and negative patients. Age and gender were no different between the two groups. Duration of HD was significantly longer in $H$. pylori-negative patients than in $H$. pylori-positive patients. There was no difference in the prescription of H2RA, mucosal protective drugs, NSAIDs and prednisolone between $H$. pylori-positive and negative patients. Although serum level of PG I was not different between the two groups, H. pylori-positive group had significantly higher serum level of PG II and a significantly lower PG I/II ratio than $H$. pylori-negative group. 


\section{Comparison of endoscopic findings between $H$. pylori-positive and negative patients}

Endoscopic findings of $H$. pylori-positive and negative patients are shown and compared in Table 2. The prevalence of neither duodenal erosion, gastric ulcer, duodenal ulcer, gastric antral vascular ectasia nor malignant neoplasm was statistically different between the two groups. However, all the patients with malignant neoplasm belonged to H. pylori-positive group. In contrast, gastric erosion was found in $79 \mathrm{H}$. pylori-negative patients, while it was detected in $34 \mathrm{H}$. pylori-positive patients (68\% vs. $42 \%$, p=0.0004). Although the difference did not reach a statistical significance, there was also a trend towards higher prevalence of reflux esophagitis in $H$. pylori-negative patients than in $H$. pylori-positive patients $(\mathrm{p}=0.0552)$. Relationship among $H$. pylori infection, endoscopic findings and duration of $H D$

Figure 1 compares duration of HD between any two groups classified by the presence or absence of esophagogastroduodenal mucosal lesions. Duration of HD was not different between patients with and without gastric erosion, gastric ulcer or duodenal erosion. On the other hand, patients with reflux esophagitis had a longer duration of HD than those without (11.9 \pm 9.7 years vs. $7.1 \pm 6.8$ years).

Figure 2 indicates the prevalence of $H$. pylori infection and the prevalence of gastric erosion among four groups of patients classified by every four-year duration of $\operatorname{HD}(\leq 4,>4$ and $\leq 8,>8$ and $\leq 12$, and $>12$ years). As shown in the figure, the prevalence of $H$. pylori infection tended to decrease according to the increase in the duration of $\mathrm{HD}(\mathrm{p}=0.055)$, while the prevalence of gastric erosion was slightly and insignificantly higher in patients with longer period of HD.

\section{Multivariate analysis for esophagogastroduodenal mucosal lesions}

Adjusted odds ratios (OR) for esophagogastroduodenal mucosal lesions were calculated by using logistic regression analyses. The results are shown in Table 3. As shown in the table, H. pylori infection was protective against gastric erosion (OR $0.38 ; 95 \%$ confidence interval 0.21-0.70) in our patients on HD. In contrast, the longer duration of HD was an independent risk factor for reflux esophagitis (OR 1.09; 95\% confidence interval 1.02-1.15). In addition, 
NSAIDs intake was calculated to be a marginal risk factor for gastric ulcer (OR 2.67; 95\% confidence interval 1.00-7.14).

\section{Discussion}

The results of our investigation indicated that in patients on HD, 1) the duration of HD was shorter in patients with $H$. pylori infection than in those without, 2) the infection was protective against gastric erosion, and 3) long-term HD was a risk factor for reflux esophagitis in patients on HD. Although it has been shown that chronic renal failure, either prior to renal transplantation or on HD, is a predisposing factor for gastroduodenal mucosal lesions, ${ }^{16,17}$ it still remains controversial as to the role of $H$. pylori infection in the pathogenesis of the lesions. Furthermore, a possible contribution of HD on $H$. pylori status has not yet been concluded. ${ }^{17-20}$ We believe our investigation to be the largest study, which evaluated esophagogastroduodenal mucosal lesions and $H$. pylori infection simultaneously in patients on HD.

The role of $H$. pylori in the pathogenesis of gastric erosion still remains unclear. Some investigators reported that $H$. pylori infection was associated with gastric erosion, ${ }^{21,22}$ while others found no such correlation. ${ }^{23,24}$ It is widely accepted that gastric erosion occurs after successful eradication of H. pylori. ${ }^{25}$ Miyake et al. ${ }^{25}$ suggested that the pathogenesis of gastric erosions involves a recovery of acid secretion after eradication of $H$. pylori. Our present study revealed that the absence of $H$. pylori infection is unequivocally a risk factor for gastric erosion in patients on maintenance HD, suggesting that gastric erosion is closely associated with the enhanced gastric acid in patients on HD. However, despite the decrease in the prevalence of $H$. pylori infection, the increase in the prevalence of gastric erosion remained insignificant according to the duration of HD in the present investigation. It thus seems likely that in addition to $H$. pylori infection humoral abnormalities, such as hypergastrinemia and high ammonia levels induced by renal insufficiency, damage gastric mucosa in patients on HD. ${ }^{26,27}$

Although $H$. pylori eradication leads to a decrease in the recurrence of peptic ulcer in general population, ${ }^{28}$ there have been no follow-up studies investigating the clinical 
implication of $H$. pylori eradication in patients on HD. Our current results seem to suggest that eradication of $H$. pylori increase the risk of developing gastric erosion in patients on HD. Some investigators reported that gastric erosions are the cause of overt upper gastrointestinal bleeding in up to $16-23 \%$ of patients examined by endoscopy. ${ }^{29,30}$ A follow-up study of 117 patients with gastric erosions for 17 years by Toljamo et al. ${ }^{24}$ revealed that peptic ulcer developed in $20 \%$ of the patients. Because gastrointestinal bleeding can be a life-threatening complication of ESRF, ${ }^{2}$ our data would suggest eradication of $H$. pylori to be hazardous for patients on HD.

Both $H$. pylori and NSAIDs are major causative factors for gastroduodenal mucosal lesions. ${ }^{5,31,32}$ Our present study showed that $H$. pylori status did not affect the prevalence of gastric ulcer, duodenal ulcer or duodenal erosion in patients on HD. These observations, together with the fact that H2RAs were protective against mucosal lesions, strongly suggest metabolites other than gastric acids to play a role in the occurrence of gastroduodenal mucosal lesion in patients on HD. This hypothesis is supported by experimental studies showing an increase in acid back-diffusion and nitric oxide overproduction in the gastric mucosa of uremic rats. ${ }^{33,34}$ In addition, dysregulation of endocrine or paracrine peptides, such as cholecystokinin, neurotensin and glucagons, and alterations in electrolytes including hypercalcemia and hypokalemia during the uremic state seem to be related to the mucosal lesions. ${ }^{35}$

There have been descriptions that long-term dialysis reduced the prevalence of $H$. pylori infection, ${ }^{36-38}$ while others found no such correlations. ${ }^{39,40}$ Nakajima et al. ${ }^{37}$ reported that in Japanese patients on HD the mean duration of HD was significantly longer in $H$. pylori-negative patients than in $H$. pylori-positive patients. More recently, Sugimoto et al. ${ }^{38}$ have shown that the prevalence of $H$. pylori infection serially decreased within four years in identical patients on HD, and this was especially the case for patients on HD for less than four years. In our investigation, such an inverse association between $H$. pylori and HD was again confirmed, and such a trend was obvious in patients on HD for more than 8 years. Even though spontaneous disappearance of $H$. pylori does occur in general population with a rate of $0.6 \%$ 
per patient-year, ${ }^{41}$ patients on HD are more likely to be in a condition of $H$. pylori eradication, because those patients are prone to be at higher serum concentrations of antibiotics than general population.

In a cross sectional study of patients with ESRF, Moustafa et al. ${ }^{42}$ showed a close association of $H$. pylori with atrophic gastritis. However, the investigators failed to show any significant correlation between endoscopic mucosal lesions and histological grade of atrophy. Although serum PGs have been shown to be excellent markers for $H$. pylori infection and gastric mucosal atrophy in general population, ${ }^{43,44}$ few studies have measured serum PG levels in patients on HD. ${ }^{45-47}$ In our patients on HD, those with H. pylori infection had a higher serum PG II level and a lower PG I/II ratio than those without the infection. Our results thus suggest that PG II and PG I/II ratio is predictive of gastric mucosal atrophy even in patients on HD, and that there may be an inverse correlation between the atrophy and mucosal lesions in patients on HD.

It is widely accepted that reflux esophagitis is associated with $H$. pylori infection in general population. ${ }^{48,49}$ However, there have been only two studies that investigated the correlation between $H$. pylori infection and reflux esophagitis in patients with ESRF. ${ }^{16,50}$ In a case-control study by Cekin et al., ${ }^{50}$ H. pylori infection has been shown to be protective against reflux esophagitis in patients on HD, while reflux esophagitis was found regardless of $H$. pylori infection in another study of patients prior to renal transplantation. ${ }^{16}$ From the results of the present investigation, it was suggested that long-term HD was an independent risk factor of reflux esophagitis. This result may be a consequence of a decrease in $H$. pylori infection rate, because there was a trend towards lower prevalence of reflux esophagitis in $H$. pylori positive patients than in $H$. pylori negative patients.

UBT is one of the most accurate procedures for the diagnosis of $H$. pylori infection, with the sensitivity, specificity, positive and negative predictive values of $97.7 \%, 98.4 \%, 98.5 \%$ and $97.6 \%$, respectively. ${ }^{51}$ However, we may have underestimated the prevalence of $H$. pylori infection in the present investigation, because we did not apply another diagnostic procedure 
for our subjects. It thus seems possible that false negative H. pylori infection might have contributed to the insignificant difference in the prevalence of acid-related esophagogastroduodenal mucosal lesions in the present investigation.

In conclusion, our endoscopic analysis of 194 patients on HD indicated that gastric erosion is a mucosal lesion commonly occurs in patients on HD and that long-term HD increases the risk of reflux esophagitis. The high prevalence of gastric erosion may be explained partly by decrease in $H$. pylori infection during the clinical course of maintenance HD. Our results thus suggest $H$. pylori infection to be protective against esophagogastric mucosal lesions in patients on HD. However, it should also be noted that malignant neoplasm of the stomach was found exclusively in patients with $H$. pylori infection, which has been confirmed to be predisposing to gastric cancer and malignant lymphoma. ${ }^{52,53}$ Because our investigation was based on a cross-sectional analysis, prospective and interventional studies are further needed to discuss the appropriateness of $H$. pylori eradication in patients on HD.

\section{Acknowledgement}

This study was undertaken with corporation by the following nephrologists and gastroenterologists in Fukuoka, Japan: Dr. T. Yanase (Yanase Internal Medicine Clinic), Dr. H. Goto and Dr. N. Ishikawa (Ekisaikai Moji Hospital), Dr. S. Nakamura (Kokura Daiichi Hospital), Dr. C. Miishima (Miishima Internal Medicine Clinic), Dr. S. Kiyama (Kiyama Internal Medicine Clinic), Dr. T. Ando (Fukuoka Red Cross Hospital), Dr. T. Iwamoto (Iwamato Internal Medicine Clinic), Dr. R. Katafuchi (Gofukumachi Clinic), Dr. S. Fujimi (Fukuoka Renal Clinic), Dr. Y. Oh (Hirao Clinic), Dr. H. Tanaka (Mojiko Renal Clinic), Dr. K. Morishita and Dr. Y. Matsumoto (Hakujyuji Hospital), Dr. H. Tsuruta and Y. Mochizuki (Nippon Steel Yawata Memorial Hospital), Dr. K. Motomura (Motomura Internal Medicine Clinic), Dr. T. Komota (Komota Clinic), Dr. S. Tomooka (Hakozaki Park Internal Medicine Clinic), Dr. S. Fuyuno (Nabatake Fuyuno Clinic), Dr. S. Inutsuka (Karatsu Medical Center), Dr. S. Ayabe (Chihaya Hospital), Dr. Y. Jo (Kimura Hospital), Dr. H. Ohgushi (Ohgushi 
Gastrointestinal Clinic) and Dr. N. Masuda (Kashii Gastrointestinal Clinic). 


\section{References}

1. Gladziwa U, Bares R, Klotz U, Dakshinamurty KV, Ittel TH, Seiler KU, et al. Pharmacokinetics and pharmacodynamics of cisapride in patients undergoing hemodialysis. Clin Pharmacol Ther 1991;50:673-81.

2. Fabian G, Szigeti N, Kovacs T, Nagy J. An unusual multiplex cause of severe gastrointestinal hemorrhage in a haemodialysed patient. Nephrol Dial Transplant 2000;15:1869-71.

3. Doherty CC. Gastrointestinal bleeding in dialysis patients. Nephron 1993;63:132-6.

4. Kang JY, Ho KY, Yeoh KG, Guan R, Wee A, Lee E, et al. Peptic ulcer and gastritis in uraemia, with particular reference to the effect of Helicobacter pylori infection. J Gastroenterol Hepatol 1999;14:771-8.

5. Graham DY, Lew GM, Klein PD, Evans DG, Evans DJ Jr, Saeed ZA, et al. Effect of treatment of Helicobacter pylori infection on the long-term recurrence of gastric and duodenal ulcer: A randomized, controlled study. Ann Intern Med 1992;116:705-8.

6. Loffeld RJ, Peltenburg HG, vd Oever H, Stobberingh E. Prevalence of Helicobacter pylori antibodies in patients on chronic intermittent hemodialysis. Nephron 1991;59:250-3.

7. Jaspersen D, Fassbinder W, Heinkele P, Kronsbein H, Schorr W, Raschka C, et al. Significantly lower prevalence of Helicobacter pylori in uremic patients than in patients with normal renal function. J Gastroenterol 1995;30:585-8.

8. Yildiz A, Besisik F, Akkaya V, Sever MS, Bozfakioglu S, Yilmaz G, et al. Helicobacter pylori antibodies in hemodialysis patients and renal transplant recipients. Clin Transplant 1999;13:13-6.

9. Luzza F, Imeneo M, Maletta M, Mantelli I, Tancre D, Merando G, et al. Helicobacter pylori-specific IgG in chronic haemodialysis patients: Relationship of hypergastrinaemia to positive serology. Nephrol Dial Trasplant 1996;1:120-4. 
10. Fabrizi F, Martin P, Dixit V, Quan S, Brezina M, Abbey H, et al. Epidemiology of Helicobacter pylori in chronic haemodialysis patients using the RIBA H. pylori SIA. Nephrol Dial Transplant 1999;14:1929-33.

11. Laine L, Estrada R, Trujillo M,Knigge K, Fennerty MB. Effect of proton-pump inhibitor therapy on diagnostic testing for Helicobacter pylori. Ann Intern Med 1998;129:547-50.

12. World Organisation of Digestive Endoscopy. http://www.omed.org/

13. Miwa H, Yokoyama T, Hori K, Sakagami T, Oshima T, Tomita T, et al. Interobserver agreement in endoscopic evaluation of esophagitis using a modified Los Angels classification incorporating grades $\mathrm{N}$ and $\mathrm{M}$ : a validation study in a cohort of Japanese endoscpists. Dis Esophagitis 2008;21:355-63.

14. Hoshihara Y, Hashimoto M. Endoscopic classification of reflux esophagitis (in Japanese with English abstract). Nippon Rinsho 2000;58:1808-12.

15. Oishi Y, Kiyohara Y, Kubo, Tanaka K, Tanizaki Y, Ninomiya T, et al. The serum pepsinogen test as a predictor of gastric cancer. The Hisayama study. Am J Epidemiol 2006;163:629-37.

16. Sotoudehmanesh R, Ali Asgari A, Ansari R, Nouraie M. Endoscopic findings in end-stage renal disease. Endoscopy 2003;35:502-5.

17. Khedmat H, Ahmadzad-Asl M, Amini M, Lessan-Pezeshki M, Einollahi B, Pourfarziani V, et al. Gastro-duodenal lesions and Helicobacter pylori infection in uremic patients and renal transplant recipients. Transplant Proc 2007;39:1003-7.

18. Abu Farsakh NA, Roweily E, Rababaa M, Butchoun R. Evaluation of the upper gastrointestinal tract in uraemic patients undergoing haemodialysis. Nephrol Dial Transplant 1996;11:847-50.

19. Tsukada K, Miyazaki T, Katoh H, Yoshikawa M, Masuda N, Ojima H, et al. Helicobacter pylori infection in hemodialysis patients. Hepatogastroenterology 2003;50:2255-8. 
20. Al-Muelio SH. Gastroduodenal lesions and Helicobacter pylori infection in hemodialysis patients. Saudi Med J 2004;25:1010-4.

21. Zhang C, Yamada N, Wu YL, Wen M, Matsuhisa T, Matsukura N. Helicobacter pylori infection, glandular atrophy and intestinal metaplasia in superficial gastritis, gastric erosion, erosive gastritis, gastric ulcer and early gastric cancer. World J Gastroenterol 2005;11:791-6.

22. Kamada T, Sugiu K, Hata J, Kusunoki H, Hamada H, Kido S, et al. Evaluation of endoscopic and histological findings in Helicobacter pylori-positive Japanese young adults. J Gastroenterol Hepatol 2006;21:258-61.

23. Kang JY, Wee A, Choong HL, Wu AY. Erosive prepyloric changes in patients with end-stage renal failure undergoing maintenance dialysis treatment. Scand J Gastroenterol 1990;25:746-50.

24. Toljamo KT, Niemelä SE, Karttunen TJ, Karvonen AL, Lehtola JK. Clinical significance and outcome of gastric mucosal erosions: A long-term follow-up study. Dig Dis Sci 2006;51:543-7.

25. Miyake K, Tsukui T, Futagami S, Tatsuguchi A, Shinoki A, Hiratsuka T, et al. Effect of acid suppression therapy on development of gastric erosions after cure of Helicobacter pylori infection. Aliment Phamacol Ther 2002;16(Suppl. 2):210-6.

26. Neithercut WD, Rowe PA, el Nujumi AM, Dahill S, McColl KE. Effect of Helicobacter pylori infection on intragastric urea and ammonium concentrations in patients with chronic renal failure. J Clin Pathol 1993;46:544-7.

27. Gur G, Boyacioglu S, Gul C, Turan M, Gursoy M, Baysal C, et al. Impact of Helicobacter pylori infection on serum gastrin in haemodialysis patients. Nephrol Dial Transplant 1999;14:2688-91.

28. Van der Hulst RW, Rauws EA, Koycu B, Keller JJ, Bruno MJ, Tijssen JG, et al. Prevention of ulcer recurrence after eradication of Helicobacter pylori: a prospective long-term follow-up study. Gastroenterology 1997;113:1082-6. 
29. Laine L, Weinstein WM. Subepithelial hemorrhages and erosions of human stomach. Dig Dis Sci 1988;33:490-503.

30. Silverstein FE, Girbert DA, Tedesco FJ, Buenger NK, Persing J. The National ASGE survey on upper gastrointestinal bleeding. II. Clinical prognostic factors. Gastrointest Endosc 1981;27:80-93.

31. Marshall BJ, Warren JR. Unidentified curved bacilli in the stomach of patients with gastritis and peptic ulcer. Lancet 1984;1:1311-5.

32. Graham DY, Smith JL. Gastroduodenal complications of chronic NSAID therapy. Am J Gastroenterol 1988;83:1081-4.

33. Quintero E, Kaunitz J, Nishizaki Y, De Giorgio R, Sternini C, Guth PH. Uremia increases gastric mucosal permeability and acid back-diffusion in the rat. Gastroenterology 1992;103:1762-8.

34. Mendez A, Fernandez M, Barrios Y, Lopez-Coviella I, Gonzalez-Mora JL, Del Rivero $\mathrm{M}$, et al. Constitutive NOS isoforms account for gastric mucosal NO overproductions in uremic rats. Am J Physiol 1997;272:G894-901.

35. Ravelli AM. Gastrointestinal function in chronic renal failure. Pediatr Nephrol 1995;9:756-62.

36. Munoz de Bustillo E, Sanchez Tomero JA, Sanz JC, Moreno JA, Jimenez I, Lopez-Brea M, et al. Eradication and follow-up of Helicobacter pylori infection in hemodialysis patients. Nephron 1998;79:55-60.

37. Nakajima F, Sakaguchi M, Amemoto K, Oka H, Kubo M, Shibahara N, et al. Prevalence of Helicobacter pylori antibodies in long-term dialysis patients. Nephrology 2004;9:73-6.

38. Sugimoto M, Sakai K, Kita M, Imanishi J, Yamaoka Y. Prevalence of Helicobacter pylori infection in long-term hemodialysis patients. Kidney Int 2009;75:96-103. 
39. Özgur O, Boyacioglu S, Ozdogan M, Gur G, Telatar H, Haberal M. Helicobacter pylori infection in haemodialysis patients and real transplant recipients. Nephrol Dial Transplant 1997;12:289-91.

40. Huang JJ, Huang CJ, Ruaan MK, Chen KW, Yen TS, Sheu BS. Diagnostic efficacy of (13) C-urea breath test for Helicobacter pylori infection in hemodialysis patients. Am J Kidney Dis 2000;36:124-9.

41. Valle J, Kekki M, Sipponen P, Ihamaki T, Siurala M. Long-term course and consequence of Helicobacter pylori gastritis. Results of a 32-year follow-up study. Scand J Gastroenterol 1996;31:546-50.

42. Moustafa FE, Khalil A, Abdel Wahab M, Sobh MA. Helicobacter pylori and uremic gastritis: a histopathologic study and a correlation with endoscopic and bacteriologic findings. Am J Nephrol 1997;17:165-71.

43. Biasco G, Paganelli GM, Vaira D, Holton J, Di Febo G, Brillanti S, et al. Serum pepsinogen I and II concentrations and IgG antibody to Helicobacter pylori in dyspeptic patients. J Clin Pathol 1993;46:826-8.

44. Wagner S, Haruma K, Gladziwa U, Soudah B, Gebel M, Bleck J, et al. Helicobacter pylori infection and serum pepsinogen $\mathrm{A}$, pepsinogen $\mathrm{C}$, and gastrin in gastritis and peptic ulcer: significance of inflammation and effect of bacterial eradication. Am J Gastroenterol 1994;89:1211-8.

45. Nakahama H, Tanaka Y, Shirai D, Nishihara F, Takamitsu Y, Nakanishi T, et al. Elevated serum pepsinogens in chronic renal failure patients. Nephron 1995;70:211-6.

46. Tamura H, Tokushima H, Murakawa M, Matsumura O, Itoyama S, Mitarai T, et al. Influence of Helicobacter pylori on serum pepsinogen concentrations in dialysis patients. Nephrol Dial Transplant 1999;14:113-7.

47. Araki H, Miyazaki R, Matsuda T, Gejyo F, Koni I. Significance of serum pepsinogens and their relationship to Helicobacter pylori infection and histological gastritis in dialysis patients. Nephrol Dial Transplant 1999;14:2669-75. 
48. Labenz J, Blum AL, Bayerdorffer E, Meining A, Stolte M, Borsch G. Curing Helicobacter pylori infection in patients with duodenal ulcer may provoke reflux esophagitis. Gastroenterology 1997;112:1442-7.

49. Koike T, Ohara S, Sekine H, Iijima K, Kato K, Shimosegawa T, et al. Helicobacter pylori infection inhibits reflux esophagitis by inducing atrophic gastritis. Am J Gastroenterol 1999;94:3468-72.

50. Cekin AH, Boyacioglu S, Gursoy M, Bilezikci B, Gur G, Akin ED, et al. Gastroesophageal reflux disease in chronic renal failure patients with upper GI symptoms: multivariate analysis of pathogenic factors. Am J Gastroenterol 2002;97:1352-6.

51. Ohara S, Kato M, Saito M, Fukuda S, Kato C, Hamada S, et al. Comparison between a new 13C-urea breath test, using a film-coated tablet, and the conventional 13C-urea breath test for the detection of Helicobacter pylori infection. J Gastroenterol 2004;39:621-8.

52. Wotherspoon AC, Doglioni C, Diss TS, Pan L, Moschini A, de Boni M, et al. Regression of primary low-grade B-cell gastric lymphoma of mucosa-associated lymphoid tissue type after eradiation of Helicobacter pylori. Lancet 1993;342:575-7.

53. Fukase K, Kato M, Kikuchi S, Inoue K, Uemura N, Okamoto S, et al. Effect of eradiation of Helicobacter pylori on incidence of metachronous gastric carcinoma after endoscopic resection of early gastric cancer: an-open label, randomized, controlled trial. Lancet 2008;372:392-7. 
Table 1. Comparison of clinical features between two groups

\begin{tabular}{lccc}
\hline & $\begin{array}{c}\text { HP-positive } \\
(\mathrm{n}=81)\end{array}$ & $\begin{array}{c}\text { HP-negative } \\
(\mathrm{n}=117)\end{array}$ & P value \\
\hline Age (yrs) & $62.4 \pm 10.1$ & $60.5 \pm 12.6$ & $\mathrm{NS}$ \\
Gender (male/female) & $52 / 29$ & $64 / 53$ & $\mathrm{NS}$ \\
Duration of hemodialysis (yrs) & $6.1 \pm 5.8$ & $8.6 \pm 8.0$ & 0.0277 \\
Medication & & & \\
$\quad$ Histamine-2 receptor antagonist & $38(47 \%)$ & $55(47 \%)$ & $\mathrm{NS}$ \\
$\quad$ Mucosal protective drugs & $29(36 \%)$ & $52(44 \%)$ & $\mathrm{NS}$ \\
$\quad$ Non-steroidal anti-inflammatory drugs & $14(17 \%)$ & $24(21 \%)$ & $\mathrm{NS}$ \\
$\quad$ Prednisolone & $2(3 \%)$ & $9(8 \%)$ & $\mathrm{NS}$ \\
Pepsinogen I (pg/ml) & $277.6 \pm 181.3$ & $257.9 \pm 144.0$ & $\mathrm{NS}$ \\
Pepsinogen II (pg/ml) & $45.0 \pm 33.6$ & $22.0 \pm 13.2$ & $<0.0001$ \\
Pepsinogen I/II & $6.9 \pm 3.9$ & $12.0 \pm 4.1$ & $<0.0001$ \\
\hline
\end{tabular}

NS; not significant 
Table 2. Comparison of endoscopic findings between two groups

\begin{tabular}{lccc}
\hline Esophagogastroduodenal mucosal lesion & $\begin{array}{c}\text { HP-positive } \\
(\mathrm{n}=81)\end{array}$ & $\begin{array}{c}\text { HP-negative } \\
(\mathrm{n}=117)\end{array}$ & P value \\
\hline Gastric erosion & $34(42 \%)$ & $79(68 \%)$ & 0.0004 \\
Duodenal erosion & $12(15 \%)$ & $23(20 \%)$ & $\mathrm{NS}$ \\
Gastric ulcer & $12(15 \%)$ & $16(14 \%)$ & $\mathrm{NS}$ \\
Duodenal ulcer & $5(6 \%)$ & $9(8 \%)$ & $\mathrm{NS}$ \\
Reflux esophagitis & $4(5 \%)$ & $16(14 \%)$ & 0.0552 \\
Gastric antral vascular ectasia & $0(0 \%)$ & $1(1 \%)$ & $\mathrm{NS}$ \\
Malignant neoplasm & $3(4 \%)$ & $0(0 \%)$ & $\mathrm{NS}$ \\
\hline
\end{tabular}

NS; not significant 
Table 3. Adjusted odds ratio (95\% confidence intervals) of independent predictors for esophagogastroduodenal mucosal lesions

\begin{tabular}{lcccc}
\hline & $\begin{array}{c}\text { Reflux } \\
\text { esophagitis }\end{array}$ & $\begin{array}{c}\text { Gastric } \\
\text { ulcer }\end{array}$ & $\begin{array}{c}\text { Duodenal } \\
\text { erosion }\end{array}$ & $\begin{array}{c}\text { Gastric } \\
\text { erosion }\end{array}$ \\
\hline Age & $0.99(0.95-1.03)$ & $1.00(0.96-1.04)$ & $0.98(0.95-1.01)$ & $1.00(0.98-1.03)$ \\
Gender & $1.72(0.63-4.69)$ & $0.68(0.28-1.65)$ & $0.98(0.45-2.12)$ & $1.18(0.64-2.17)$ \\
Duration of hemodialysis & $1.09 *(1.02-1.15)$ & $1.01(0.95-1.07)$ & $0.98(0.93-1.04)$ & $1.02(0.98-1.07)$ \\
Non-steroidal anti-inflammatory drugs & $0.34(0.59-1.92)$ & $2.67 \dagger(1.00-7.14)$ & $1.31(0.49-3.51)$ & $1.14(0.51-2.54)$ \\
Prednisolone & ND & $0.43(0.05-3.94)$ & ND & $0.93(0.25-3.51)$ \\
Histamine-2 receptor antagonist & $0.72(0.25-2.06)$ & $1.99(0.83-4.78)$ & $1.20(0.56-2.60)$ & $0.86(0.47-1.59)$ \\
Mucosal protective drugs & $1.96(0.67-5.72)$ & $1.76(0.73-4.22)$ & $0.85(0.83-1.89)$ & $1.66(0.88-3.14)$ \\
H. pylori infection & $0.41(0.13-1.32)$ & $1.15(0.50-2.73)$ & $0.66(0.30-1.45)$ & $0.38 *(0.21-0.70)$ \\
\hline
\end{tabular}

$* \mathrm{P}<0.05$, by logistic regression analysis, for analysis of odds ratio for independent predictors

$\dagger \mathrm{P}=0.05$, by logistic regression analysis, for analysis of odds ratio for independent predictors

ND; not determined 
Figure 1. Relationship between endoscopic findings and duration of hemodialysis ((A) gastric erosion, (B) gastric ulcer, (C) duodenal erosion, (D) reflux esophagitis)

(A)

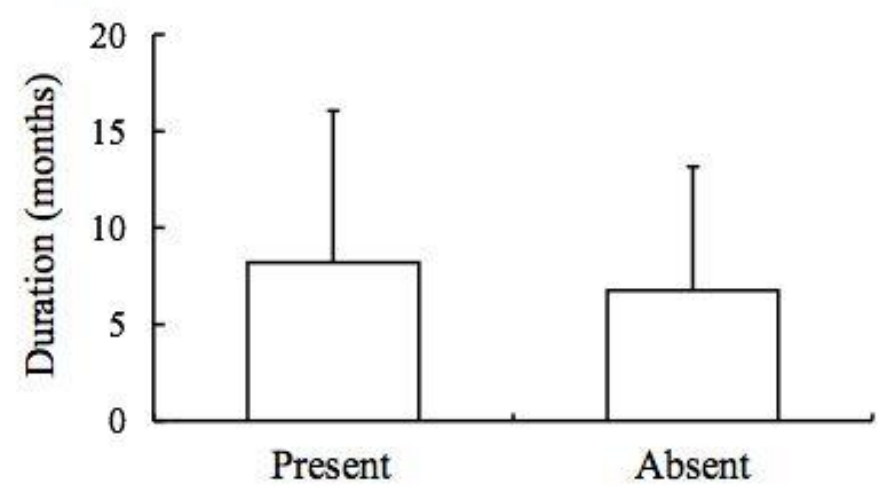

(C)

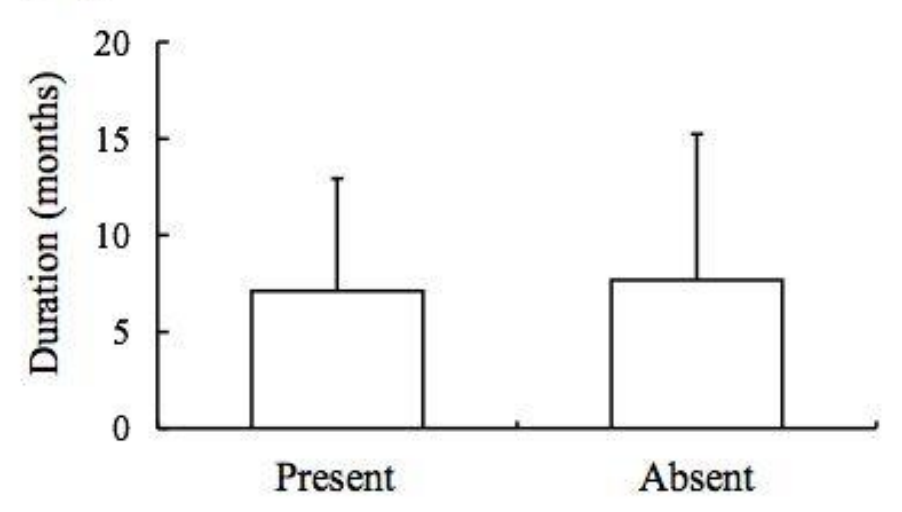

(B)

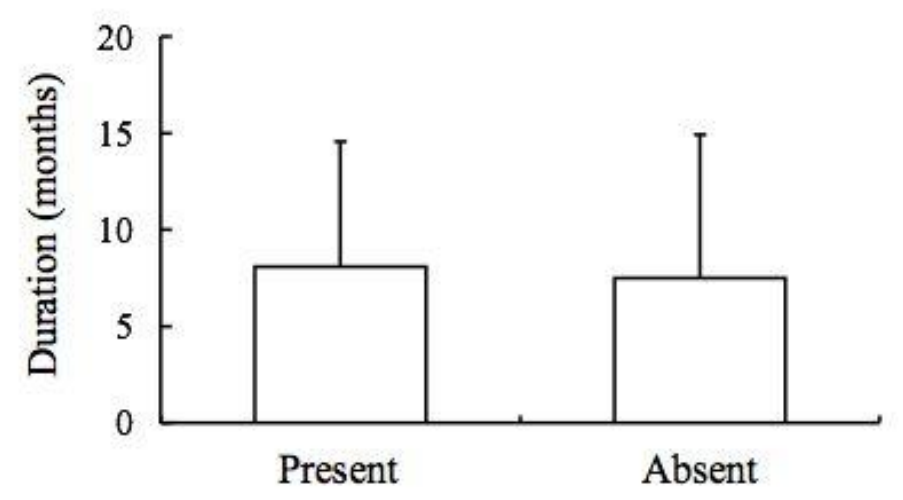

(D)

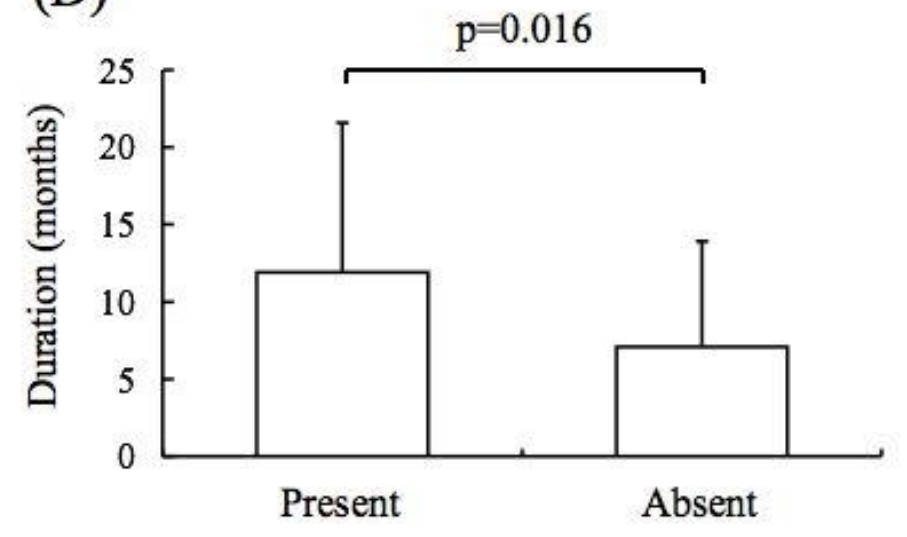


Figure 2. Relationship among $H$. pylori infection, gastric erosion and duration of hemodialysis

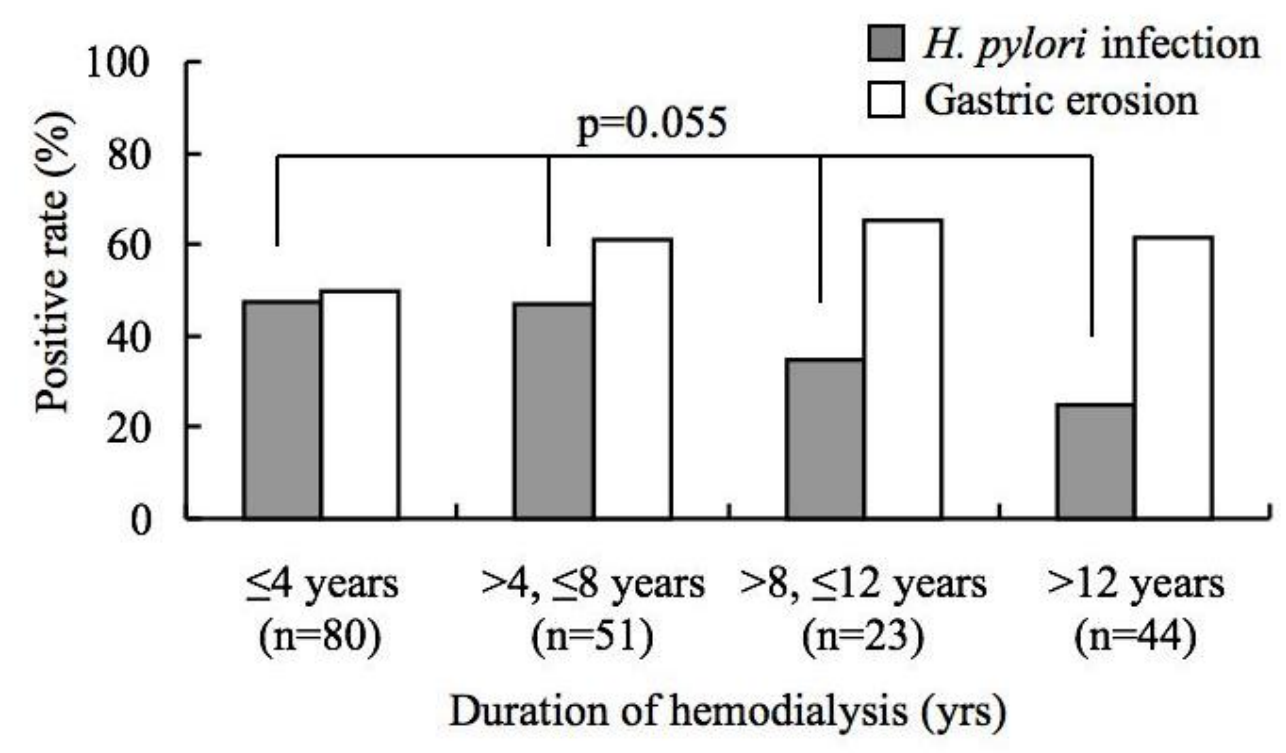

